\title{
A 100 años de la Revolución Rusa. El impacto en América Latina
} 100 years on from Russian Revolution
and its impact on Latin America

\author{
Laura Pasquali \\ Universidad Nacional de Rosario \\ Investigaciones Socio-históricas Regionales \\ (Argentina) \\ laura@pasquali.com.ar \\ Pablo Pozzi \\ Facultad de Filosofía y Letras \\ Universidad de Buenos Aires \\ (Argentina) \\ pozzipabloa@gmail.com
}

El estudio de la Revolución Rusa tiene una extensísima bibliografía historiográfica y es, posiblemente, uno de los más claros ejemplos de los vínculos entre ideología e historiografía. Para investigadores norteamericanos como Robert Service y Robert Conquest y para el sociólogo Barrington Moore Jr. la Revolución Rusa es uno de los caminos a la modernización industrial. Esta interpretación, muy difundida, hace énfasis no en lo social ni en la propiedad de los medios de producción, sino más bien, en el desarrollo económico visto como un progreso hacia la industrialización. En este sentido, no habría grandes diferencias entre una revolución industrial del siglo XIX y la industrialización llevada a cabo por la planificación soviética, excepto por el carácter forzado de esta última. Sería, así, 
una "modernización desde arriba". Para otros, como Bertram Wolfe o Robert Daniels, el énfasis se ubica en la parte política. Puesto que ponen el acento en el monopolio del poder por parte de los bolcheviques, hacen una comparación ahistórica planteando, que lejos de una ruptura, los soviéticos son la continuidad de la Rusia zarista y feudal. Para historiadores como Jean Meyer, el eje de su análisis es lo que entienden como tradiciones y patrones culturales asentados durante siglos. Desde la perspectiva liberal, está la interesante historia de Edward $\mathrm{H}$. Carr que presenta a la revolución como un producto de las contradicciones de la época desatadas por la Primera Guerra Mundial. Para otros historiadores, la revolución es considerada como un tipo de golpe de estado, exitoso ante los errores del tsarismo y el debilitamiento generado por las derrotas de la Primera Guerra Mundial. Para muchos de los anteriores, la Revolución cortó un proceso evolutivo y pacífico de modernización capitalista democrática generalmente vinculado con las reformas del ministro Piotr Stolypin, cuya confirmación sería el surgimiento de la Duma.

En cambio, desde el marxismo, la Revolución ha generado una inmensa bibliografía incluyendo el monumental trabajo de León Trotsky (posiblemente uno de las más grandes obras de historia), y los de Deutscher, Moshe Lewin, Alec Nove y otros. En general, estos estudios se centran en el proceso de lucha de clases sin dejar de lado los factores coyunturales como la Gran Guerra. Para estos autores, la revolución no era parte de un proceso inevitable, sino que se inscribía dentro de la tendencia histórica como una de las posibilidades. De ahí que el factor subjetivo (o sea el papel de los bolcheviques) fuera importantísimo para su resolución en la forma en que se dio. Dentro del marxismo conocido como vulgar (o stalinismo), se elaboró también una visión histórica vinculada con la Academia de Ciencias de la URSS, por ejemplo la Gran Historia de la Revolución de Octubre publicada por Editorial Progreso, en la cual la revolución fue producto, sobre todo, de la visión preclara de Lenin.

Por último, las hipótesis difundidas al día de hoy abarcan desde las provenientes del postmarxismo y el postmodernismo que resultan en una cierta mezcla de las anteriores. Desde el postmarxismo, y siguiendo al menchevique ruso Theodore Dan, el ruso Boris Kagarlitsky plantea la revolución como un proceso democratizador (representada por los Kadetes y los Mencheviques y algunos sectores bolcheviques) desviado por las tendencias autoritarias del bolchevismo leninista. En cambio, para la posmodernidad del tipo preconizado por François Furet, la revolución representó un retroceso en el proceso democratizador, hacia un autoritarismo similar al fascismo. En este sentido, Stalin sería la continuación lógica de Lenin.

Subyacente a todo lo anterior, y como plantea Eric Hobsbawm, ${ }^{1}$ existen una gran cantidad de preguntas de índole particularmente ahistóricas que plantean dudas de este tipo: "¿qué hubiera ocurrido si Lenin no hubiera muerto?" o "¿era inevitable la revolución?" o "¿iba Rusia camino a un capitalismo liberal en 1913?” o “¿era Lenin lo mismo que Stalin?”. Casi todos estos interrogantes apuntan, en última instancia, a explicar

1. HOBSBAWM, Eric, “¿Podemos escribir una historia de la Revolución Rusa?", en HOBSBAWM, Eric, Sobre la bistoria, Crítica, Barcelona, 2002, p 244. 
no tanto la revolución sino más bien su desarrollo posterior o sea el surgimiento del stalinismo. En general, estas preguntas encierran una respuesta preconcebida y una preferencia político-ideológica por parte del historiador. Lo cierto es que la revolución ocurrió y se desarrolló en cierta forma y no en otra, por lo que la pregunta para el historiador es: ¿por qué? Tal como señala Víctor Serge, debe tenerse en cuenta que en un fenómeno histórico existen una inmensa cantidad de posibilidades y el tema es estudiar el por qué fructificaron algunas y no otras.

Menos tratada en la historiografía ha sido la influencia de la Revolución Rusa en el proceso histórico mundial y, en nuestras latitudes, en el de América Latina. En realidad, no es que sea ignorada sino más bien que la mayoría de los estudios consideran esta influencia como algo lineal y cuasi mecánico por lo cual "el oro de Moscú" intentaba subvertir las sociedades latinoamericanas, y donde los diversos partidos comunistas eran meros apéndices de los soviéticos. Sin embargo, esto siempre fue mucho más complejo, como bien han señalado estudiosos como Fabio Grobart, Barry Carr y Rodolfo Cerdas Cruz, entre otros. ${ }^{2}$ Por suerte, en las últimas décadas, y gracias a la apertura de los archivos de la Tercera Internacional en Moscú luego a la caída de la Unión Soviética, los investigadores

2.GROBART, Fabio, "The Cuban working class movement from 1925-1933”, en Science and Society , New York, 1975, V.39, No 1, pp 73-103; CERDAS CRUZ, Rodolfo, La hoz y el machete: la internacional comunista, América Latina y la revolución en Centroamérica, Editorial Universidad Estatal a Distancia, San José de Costa Rica, 1986; CARR Barry, "Mill Occupations and Soviets: The Mobilisation of Sugar Workers in Cuba 1917-1933”, en Journal of Latin American Studies, Cambridge, 1996, V. 28, No 1, pp. 129-158. disponen de nueva documentación que está permitiendo desarrollar una visión histórica más compleja y matizada.

A simple vista, llama la atención la vastedad de la presencia del proceso soviético en la vida latinoamericana, en la cual se reconocen perspectivas políticas, sindicales y económicas. Según Eugene Gogol: "No hay duda de la profunda influencia que la Revolución Rusa ha tenido en los movimientos sociales, en pensadores-activistas revolucionarios $\mathrm{y}$, de hecho, en diversas revoluciones en América Latina en el siglo pasado. Al mismo tiempo, ha significado una herencia doble, contradictoria: la grandeza de la primera revolución socialista exitosa seguida de su trágica transformación en su opuesto: una sociedad capitalista de Estado". ${ }^{3}$

El impacto provocado por la Revolución Rusa en los países latinoamericanos se vio reflejado de maneras diferentes, pero en todos los países prendió, en mayor o menor medida, o se potenció el pensamiento y las corrientes socialistas. El efecto más notado y percibido fue el del desarrollo del movimiento revolucionario, tanto anarquista como socialista, pero su influencia fue muchísimo más amplia. En ese sentido, su influjo es apreciable en reformas como las que se plasmaron en la Constitución Mexicana de 1917, en la obra de pensadores como José Carlos Mariátegui y José Revueltas, en la de escritores y poetas como Alejo

3. GOGOL, Eugene, "La influencia de la Revolución Rusa en América Latina. Una herencia dual: revolución socialista, transformación en capitalismo de Estado", en Revista Herramienta, Buenos Aires, 2017. Disponible en: <http://www.herramienta.com.ar/content/la-influenciade-la-revolucion-rusa-en-america-latina-una-herenciadual-revolucion-socialist>. 
Carpentier, Jorge Amado y Pablo Neruda, o la de artistas como Diego Rivera y David Alfaro Siqueiros, y por supuesto en la organización de los trabajadores. De hecho, la reforma universitaria de 1918, en Argentina, es incomprensible sin tomar en cuenta las repercusiones de la Revolución Rusa en este país, al igual que las huelgas de la Patagonia Trágica de 1921/22. Del mismo modo, deben considerarse la Columna Prestes en Brasil en 1925, el levantamiento de Farabundo Martí en El Salvador en 1932, o los soviets cubanos y chilenos en la década de 1930 y tantos, pero tantos otros hechos que han determinado el desarrollo de la historia latinoamericana. Asimismo, su impacto no se limitó a sus contemporáneos, sino que también se lo puede registrar durante todo el siglo XX y hasta el día de hoy. Son múltiples las entradas que admiten la exploración sobre las consecuencias de la Revolución Rusa en América latina. La selección que presentamos aquí recorre experiencias de Chile, México, Perú y Argentina.

Centrado especialmente en indagar los fundamentos teóricos de la línea política del Movimiento de Izquierda Revolucionaria (en adelante, MIR) chileno, Igor Goicovic presenta el contexto de emergencia de esa organización y se interroga acerca de la incidencia del modelo bolchevique en ese proceso. Transita cada década, desde las primeras formas de organización obrera a fines del siglo XIX, hilvanando las especificidades locales con la realidad soviética y la del Partido Obrero Socialista primero, que poco después cambió su nombre por Partido Comunista de Chile hasta que las profundas diferencias en torno al stalinismo dieron origen al Partido Socialista de Chile.
Más adelante, se detiene especialmente en las transformaciones ocurridas en Chile durante la década de los años cincuenta, enfatizando sus efectosen los sectores populares y en el arco político de las izquierdas. En ese sentido, para el MIR (fundado en 1965) la teoría leninista del partido revolucionario y de la toma del poder era la perspectiva para interpretar y transformar la realidad chilena. En "La Revolución Bolchevique y el MIR chileno (1965-1973). Adhesiones y distancias", Goicovic realiza un minucioso trabajo sobre la prensa y los documentos de las organizaciones que investiga.

También sobre el impacto de la Revolución Rusa en la política local, Patricia Pensado presenta una investigación sobre su influencia en el Partido Comunista de México. "Imaginarios e integrados. Su artículo, "La praxis comunista de los años veinte en México", centrado especialmente en los años veinte, se ocupa de la huella que orientó en ese derrotero la relación de aquel partido con la III Internacional Comunista pero a la vez de las estrategias para concitar las voluntades de obreros y campesinos, siempre dentro del entramado que significaba la profundización de la Revolución mexicana.

Abordar las relaciones diplomáticas con la URSS en el conflictivo contexto de la entreguerra, le permite a Pensado inmiscuirse en las tensas relaciones entre la embajada soviética en México, los gobiernos de Calles y Portes Gil y el Partido Comunista Mexicano. Asimismo, analiza las estrategias del PCM para desarrollarse en la clase obrera y en el campesinado a través de la prensa partidaria y memorias del sindicalismo. 
Una de las formas en que se manifestó el impacto de la Revolución Rusa en Argentina es abordada por Mariana Mastrangelo en "La Revolución Rusa en la memoria de los comunistas cordobeses". El artículo se focaliza en las memorias de tres militantes organizadores del Partido Comunista en Córdoba y también del movimiento obrero de esa provincia. La particularidad de esto es que esas Memorias, son resultado de un homenaje realizado por el mismo Partido a esos militantes en los años setenta del siglo $\mathrm{XX}$.

Los ejes con que Mastrángelo propone el estudio son las lecturas sobre la Revolución Rusa, la formación del Partido Comunista en Córdoba y la movilización obrera y sindical que tuvo como protagonistas a los homenajeados por el mismo Partido, buceando en la estructura interna de cada relato y articulándolos con la biografía de cada militante.

Finalmente, Martín Salinas se ocupa de la recepción de la literatura rusa por parte de José Carlos Mariátegui en los años veinte, sosteniendo que sus propuestas críticas en el convulsionado proceso abierto por la Revolución Rusa indican una reinterpretación de la historia considerada como un proceso abierto. Para Salinas, la Revolución adquiere centralidad en la interpretación de Mariátegui sobre la historia de la literatura peruana y, desde ese enfoque, habría leído el momento atravesado por el avance de las ideas fascistas, la crisis económica de posguerra y la oleada revolucionaria europea de entreguerras.

$\mathrm{El}$ autor insiste sobre el significado que tiene la literatura como manifestación del nuevo orden en Mariátegui, y destaca la centralidad de la nueva literatura europea en su perspectiva literaria y política, presente en Siete ensayos de interpretación de la realidad peruana, aunque Salinas también recurre a buena parte de la producción del peruano como crítico y como político.

Queremos agradecer a las autoras y los autores por sus valiosas contribuciones y compromiso con esta propuesta.

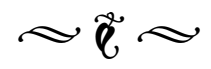




\section{Bibliografía}

BETTELHEIM, Charles, Class Struggles in the USSR. Monthly Review Press, New York 1976.

CARR Barry, "Mill Occupations and Soviets: The Mobilisation of Sugar Workers in Cuba 1917-1933", en Journal of Latin American Studies, Cambridge, 1996, V. 28, № 1, pp. 129-158.

CARR, Edward, La Revolución Rusa. Madrid, Alianza, 2014

CERDAS CRUZ, Rodolfo, La hoz y el machete: la internacional comunista, América Latina y la revolución en Centroamérica, Editorial Universidad Estatal a Distancia, San José de Costa Rica, 1986.

COCKBURN, Patrick, Getting Russia Wrong, Verso Books, London 1989.

CONQUEST Robert, "Preface" The Great Terror: A Reassessment: 40th Anniversary Edition, Oxford University Press, Cary/New York, 2007.

DAN, Theodore, The Origins of Bolsherism. Schocken Books, New York, 1970.

DANIELS, Robert, Red October. The Bolshevik Revolution of 1917, Charles Scribner's and Sons, New York, 1967.

DEUTSCHER, Isaac, El profeta armado, 1979-1921, Ediciones LOM, Santiago de Chile, 2007.

DJILAS, Milovan, La Nueva Clase. Análisis del régimen comunista, Sudamericana, Buenos Aires, 1963.

FURET, François, Fascismo y comunismo, Alianza Editorial, Madrid, 1998.

GOGOL, Eugene,"La influencia de la Revolución Rusa en América Latina. Una herencia dual: revolución socialista, transformación en capitalismo de Estado", en Revista Herramienta, Buenos Aires, 2017. Disponible en: <http://www.herramienta.com.ar/content/la-influencia-de-la-revolucion-rusa-enamerica-latina-una-herencia-dual-revolucion-socialist $>$.

GROBART, Fabio, “The Cuban working class movement from 1925-1933”, en Science and Society , New York, 1975, V. 39, № 1, pp 73-103.

HOBSBAWM, Eric J., “¿Podemos escribir una historia de la Revolución Rusa?”, en HOBSBAWM, Eric J., Sobre la historia. Crítica, Barcelona, 2002, pp. 242-252.

KAGARLITSKY, Boris, The Thinking Reed, Verso Books, London, 1988.

KOLKO, Gabriel, Vietnam. Anatomy of Peace, Routledge, London, 1997.

LEWIN, Moshe, The Making of the Soviet System: Essays in the Social History of Interwar Russia, Pantheon Books, New York, 1985. 
MAGDOFF, Harry, “A note on 'market socialism”, en Montbly Review Archives, New York, 1995, V. 47, No 1, pp. 12-18.

MEDVEDEV, Roy, Let History Judge, Vintage Books, New York, 1973.

MEYER, Jean, Rusia y sus imperios 1894-1991, Fondo de Cultura Económica, México, 1997.

MOORE, Barrington, Jr., Los origenes sociales de la dictadura y la democracia, Ediciones Península, Barcelona, 1973.

NOVE, Alec, An Economic History of the USSR 1917-1991, Penguin Books, London, 1992.

SERVICE, Rober, A History of Modern Russia from Nicholas II to Putin, Penguin, London 2003.

SERGE, Víctor, El año I de la Revolución Rusa (1930), Siglo XXI, Madrid, 1972.

S/A, The Great October Socialist Revolution, Progress Publishers, Moscow, 1977.

TROTSKY, León, Historia de la Revolución Rusa, Madrid, Sarpe, 1985.

WOLFE, Bertram, Three Who Made a Revolution, Dell Publishing, New York, 1948. 